\title{
Drying conditions and analysis of physicochemical characteristics of Capsicum pubescens
}

\author{
Sánchez-García, C. ${ }^{\text {; }}$ Del Ángel-Coronel, O.A. ${ }^{\text {a }}$ Paniagua-Martínez, I. ; Luna- \\ Solano, G. ${ }^{\text {; }}$ Ramírez-Martínez, A. ${ }^{\text {** }}$ \\ ${ }^{a}$ Department of Food Engineering. Tecnológico Nacional de México-Instituto Tecnológico Superior \\ de Huatusco, Huatusco, México. \\ ${ }^{\mathrm{b}}$ Faculty of Bioanalysis Campus Veracruz. University of Veracruz, Veracruz, México \\ c Department of Chemistry. Tecnológico Nacional de México-Instituto Tecnológico de Orizaba, \\ Orizaba, México.
}

*E-mail of the corresponding author: alejandrarm@itshuatusco.edu.mx

\begin{abstract}
Capsicum pubescens, a chili specie present in south Mexico (Veracruz state) registers upon $30 \%$ loss due to the constraints of the market. Therefore, the objective of this project was to determine the physical and chemical parameters of Capsicum pubescens as well as to evaluate the kinetics of drying of this species. Color tests revealed that the samples were the color was less affected by drying conditions ( $p>0.05)$ correspond to those dried at $60^{\circ} \mathrm{C}\left(0.5 \mathrm{~cm}\right.$ thickness), and $50^{\circ} \mathrm{C}(0.5$ and $1 \mathrm{~cm}$ thickness) which coincides with the preference of surveyed population. Thus, Capsicum pubescens may be dried under these conditions.
\end{abstract}

Keywords: Capsicum pusbescens; drying; sensorial analysis; food loss. 


\section{Introduction}

Most chile belongs to the species Capsicum annuum while four other lesser known species have also been domesticated. One of this species, the pepper tree (C. pubescens), also known as rocoto and locoto in South America, manzano or peron in Mexico, originated in the Andean highlands with extensions in Central America and Mexico [1] [2]. The varieties of this species of chile vary in shape, and the color changes from green (in its immature state) to yellow, orange or red (mature state) [3]. This species is of recent introduction to Mexico where it is cultivated in states with high elevations (1200 to $3000 \mathrm{~m}$ ) including the High Mountain regions in the state of Veracruz [4]. C. pubescens is mainly cultivated in the months from August to December [5]. Despite this fact, it is highly appreciated in several Mexican states and European markets [5][6] because it is more resistant than other common chile species (C. annuum) to aphids and its particular flavor. Even though there is scarce information on its sensory qualities, it has been reported that it contains a relatively greater number of individual capsaicinoids and show more diversity in capsaicinoid profiles than other Capsicum species [2]. Moreover, its capsaicin:dihydrocapsaicin ratio is different from $C$. annuum which supports and sustain its particular flavor.

Even though C. pubescens seems to possess particular properties and its appreciated in international markets, there is scarce information regarding its conservation. Moreover, local producers from the High Mountains region in the state of Veracruz register up to $30 \%$ loss of manzano chile due to the constraints of the market. Convective drying is an excellent option to diminish $C$. pubescens loss as well as to provide national and international markets with product throughout the year. Therefore, the objective of this project was to evaluate the kinetics of drying of this species and to determine the physical and chemical parameters of Capsicum pubescens during drying. Also, a sensorial analysis of manzano chili powder obtained after drying of fresh fruit was performed.

\section{Materials and methods}

\subsection{Selection and characterization of the raw material}

Samples of Capsicum pubescens were collected in their mature state (established by the presence of intense yellow color) in a rural area called Ateopa in the municipality of Alpatlahuac, Veracruz (Mexico, 1860 m altitude) between August 2017 and January 2018. After collecting the samples they were transported to Orizaba, Veracruz to be dried. The samples were cut into slices of 0.5 and $1 \mathrm{~cm}$ thickness.

\subsection{Drying process}

Tests were conducted in a pilot plant scale vertical tray dryer (MOD-SEM-2 Polinox, MX). Drying tests were carried out at temperatures of 50,60 and $70^{\circ} \mathrm{C}$ and the air velocity was imposed at $1.2 \mathrm{~m} / \mathrm{s}$. In each test, the drying kinetics were evaluated by recording the 
moisture content change as function of time. During the drying process, samples were taken to analyze the main physical-chemical parameters ( $a_{w}$, moisture content and color) every 15 minutes during the first hour, 30 minutes in the following hour, and finally every 60 min until the water activity of the samples reached 0.6 .

\subsubsection{Effective diffusion}

The effective diffusivity of food products can be estimated by Fick's second law of diffusion. Considering the geometry of the pepper tree samples, diffusion is better estimated through the solution of Fick's equation for slab geometry. For long drying periods, this solution can be simplified to only the first term of the series as:

$$
\ln M_{R}=\ln \frac{8}{\pi^{2}}-\left(\frac{\pi^{2} D_{e f f} t}{4 L^{2}}\right)
$$

Where the moisture content was expressed as the moisture ratio $\left(M_{R}\right), D_{\text {eff }}$ corresponds to water diffusivity in $\mathrm{m}^{2} / \mathrm{s}, t$ is the time in $\mathrm{s}$ and $L$ is the thickness in $\mathrm{m}$. Moisture content ratio was calculated by means of eq. (2):

$$
M_{R}=\frac{X}{X_{0}}
$$

Where $X$ corresponds to the moisture content at any time in g water/g of dry solid and $X_{0}$ is the initial moisture content in $g$ water/g of dry solid. Tests were conducted in duplicate.

Drying kinetic data was adjusted to a single exponential as shown in equation 3:

$$
M_{R}=\frac{X}{X_{0}}=e^{-k t}
$$

where $k$ is a model parameter. The goodness of fit of the data to the model was evaluated by means of the $\mathrm{R}^{2}$ parameter.

\subsection{Sensorial analysis test}

Manzano chili samples were subjected to a sensorial analysis by means of an hedonic verbal test of 7 points with untrained panelists $(\mathrm{N}=150)$. The samples were presented simultaneously and later, each panelist evaluated each sample only once accompanied by Mexican yam bean (jicama) (Pachyrizus erosus). Each participant was asked to indicate how much they liked each sample, assigning an attribute according to the category reported on a scale which ranged from "I disliked it a lot" to "I really liked it a lot". The samples were coded to identify the condition in wich it was dried. After concluding each test, panelists were asked to drink water as a neutralizer to avoid interference with the next treatment. 


\subsection{Statistical analysis}

Differences between drying kinetics and physicochemical parameters of $C$. pubescens samples regarding the drying parameters as well as the significance in the preference of samples were analyzed through an ANOVA test (MiniTab, 2016).

\section{Results and discussion}

\subsection{Air drying kinetics}

Fig. 1 and 2 shows the drying kinetics of $C$. pubescens dried at two thickness ( 0.5 and 1 $\mathrm{cm}$ ) and three temperatures $\left(50,60\right.$ and $70^{\circ} \mathrm{C}$ ) and Table 1 shows the values of the rate constants for the first order kinetic parameter as well as the diffusion coefficient for each drying condition proposed.

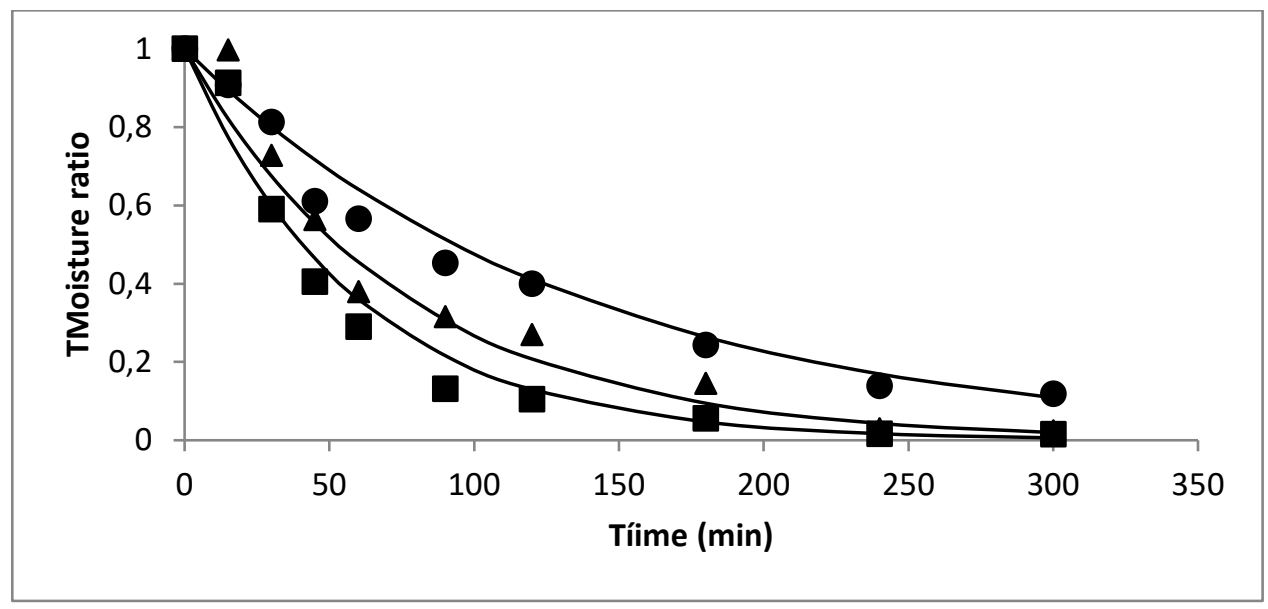

Fig. 1 Drying kinetics of C. pubescens samples of $1 \mathrm{~cm}$ thickness $\left(\triangle=70^{\circ} \mathrm{C}, \bullet=60^{\circ} \mathrm{C}, \bullet=50^{\circ} \mathrm{C}\right)$

Table 1 reveals that the diffusion coefficient is in the range of $10^{-9}-10^{-10} \mathrm{~m}^{2} / \mathrm{s}$ which is similar to the diffusion value reported by Lucio-Juárez et al (2012) for habanero chili (C. chinense) $\left(5.9470 \times 10^{-10} \mathrm{~m}^{2} / \mathrm{s}\right)$ which has similar structure to C. pubescens. In accordance with the findings of Nguyen and Price [7], the diffusion coefficients for the thicker slices (1 $\mathrm{cm})$ are greater than those for thiner slices $(0.5 \mathrm{~cm})$ which are not observed in all foodstuffs. As exposed in this last study, the rate constant from a first order kinectic drying model encompasses several mass transfer mechanisms including the diffusion of water in the falling drying rate. 


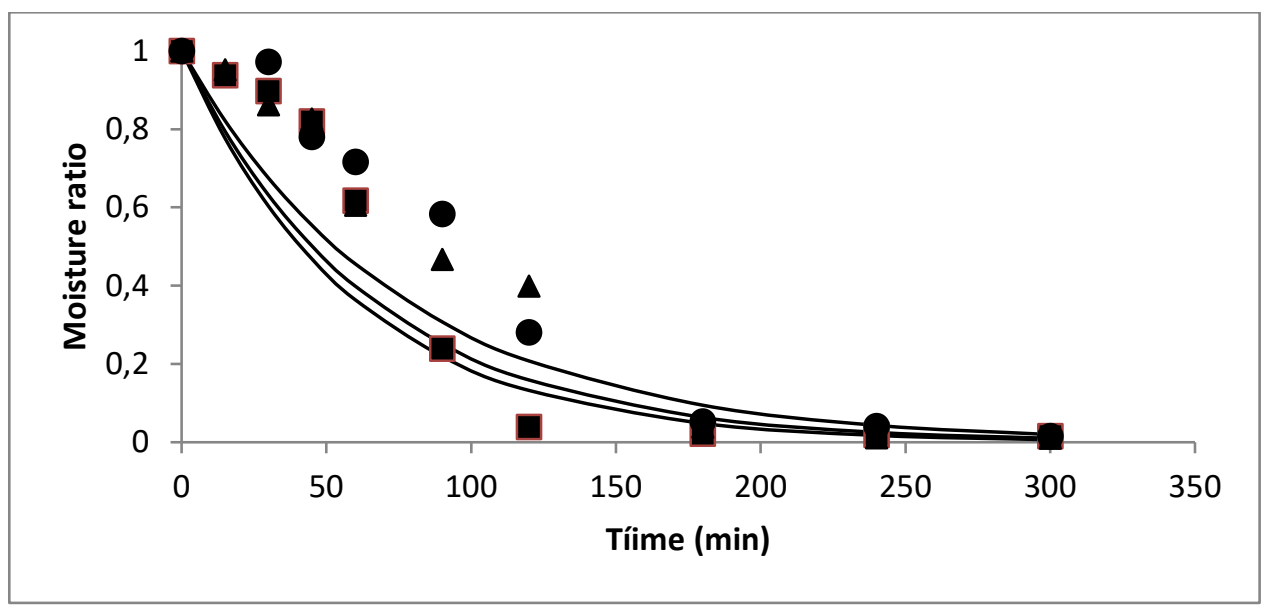

Fig. 2 Drying kinetics of $C$. pubescens samples of $0.5 \mathrm{~cm}$ thickness $\left(\triangle=70^{\circ} \mathrm{C}, \bullet=60^{\circ} \mathrm{C}, \diamond=50^{\circ} \mathrm{C}\right)$

Table 1. Rate constant and diffusion coefficient for the drying kinetics of C. pubescens

\begin{tabular}{lcc}
\hline Drying condition & Rate constant $\left(\mathbf{m i n}^{-\mathbf{1}}\right)$ & Diffusion coefficient $\left(\mathbf{m}^{\mathbf{2}} / \mathbf{s}\right)$ \\
\hline $50^{\circ} \mathrm{C}, 0.5 \mathrm{~cm}$ & 0.0152 & $6.4516 \times 10^{-10}$ \\
$50^{\circ} \mathrm{C}, 1 \mathrm{~cm}$ & 0.0075 & $1.2706 \times 10^{-9}$ \\
$60^{\circ} \mathrm{C}, 0.5 \mathrm{~cm}$ & 0.0168 & $7.1135 \times 10^{-10}$ \\
$60^{\circ} \mathrm{C}, 1 \mathrm{~cm}$ & 0.0129 & $2.1909 \times 10^{-9}$ \\
$70^{\circ} \mathrm{C}, 0.5 \mathrm{~cm}$ & 0.0177 & $7.4706 \times 10^{-10}$ \\
$70^{\circ} \mathrm{C}, 1 \mathrm{~cm}$ & 0.0149 & $2.5267 \times 10^{-9}$ \\
\hline
\end{tabular}

In the present case, the rate constant parameter for the single exponential equation (which is generally related with the diffusion coefficient) effectively represents the drying rates for the samples of $1 \mathrm{~cm}$ thickness but is less accurate for samples of $0.5 \mathrm{~cm}$ thickness (Fig. 2). Moreover, statistical analysis revealed that the water content difference beetwen samples of chili of 0.5 and $1 \mathrm{~cm}$ thickness dried at the same temperature was not significant ( $>>0.05$ ). This may be explained by the internal structure of $C$. pubescens which may play a role in the similarity of loss water at both sample thickness.

\subsection{Physicochemical parameters of samples of manazano chili (C. pubescens) during the drying process}

The color change of the different samples of manzano chili was recorded during the drying process. Table 2 shows the average value of $\Delta \mathrm{E}$ after $300 \mathrm{~min}$ at each drying condition tested for C. pubescens. Results showed that color changed significantly depending on the drying conditions at which samples were subjected $(\mathrm{p}<0.05)$. After $300 \mathrm{~min}$ the lesser color change was observed in samples dried at $60^{\circ} \mathrm{C}$ and $0.5 \mathrm{~cm}$, and $50^{\circ} \mathrm{C}$ for both sample 
thickness $(1 \mathrm{~cm}$, and $0.5 \mathrm{~cm}$ ). Color of C. pubescens (and of chili species in general) is given by carotenoids which may be affected by heat (Hernández-Ortega et al., 2015). Thus, the difference in color may also reflect the loss of carotenoids due to drying.

Regarding the water activity, after 300 min of drying all samples of manzano chili were below 0.6. Analysis test revealed that the decrease of the water activity was not significantly different among the drying conditions studied $(p>0.05)$. The lack of difference between the samples suggests that the loss of water is similar regardless the thickness. This supports the idea that there is a concentration of the water content in thiner samples due to natural causes, such as the internal structure.

Table 2. $\Delta E$ and $a_{w}$ of slices of C. pubescens (after $300 \mathrm{~min}$ ) at different drying conditions

\begin{tabular}{lcc}
\hline Drying condition & $\boldsymbol{\Delta} \mathbf{E}$ & $\boldsymbol{a}_{\boldsymbol{w}}$ \\
\hline $50^{\circ} \mathrm{C}, 0.5 \mathrm{~cm}$ & $12.26 \pm 0.12$ & $0.391 \pm 0.55$ \\
$50^{\circ} \mathrm{C}, 1 \mathrm{~cm}$ & $9.6 \pm 0.22$ & $0.524 \pm 0.71$ \\
$60^{\circ} \mathrm{C}, 0.5 \mathrm{~cm}$ & $7.79 \pm 0.03$ & $0.378 \pm 0.07$ \\
$60^{\circ} \mathrm{C}, 1 \mathrm{~cm}$ & $15.41 \pm 0.57$ & $0.367 \pm 0.21$ \\
$70^{\circ} \mathrm{C}, 0.5 \mathrm{~cm}$ & $14.24 \pm 0.09$ & $0.301 \pm 0.02$ \\
$70^{\circ} \mathrm{C}, 1 \mathrm{~cm}$ & $15.34 \pm 0.12$ & $0.405 \pm 0.10$ \\
\hline
\end{tabular}

\subsection{Sensorial analysis test}

Statistical analysis revealed that 145 out of 150 people manazano chili powder was highly desirable $(\mathrm{p}<0.05)$. We counted the type of samples that were highly accepted (I strongly prefer) by panelists, and we found that nearly $70 \%$ preferred the samples dried at $60^{\circ} \mathrm{C}$ and $0.5 \mathrm{~cm}$ thickness and $60 \%$ preferred the samples dried at $50^{\circ} \mathrm{C}$ and $1 \mathrm{~cm}$ thickness. Interestingly, this drying conditions coincide with those in which the samples showed lesser color change (Table 2). As surveyed population was invited to chose the sample as a function of its flavor, this last result suggests that population relates a good flavor with reddish color.

\section{Conclusions}

Capsicum pubescens slices dried at different drying conditions showed values of water activity lesser than 0.6 after 300 min process. The diffusion coefficient of thicker samples $(0.5 \mathrm{~cm})$ was higher than the values observed in thicker samples $(1 \mathrm{~cm})$ similarly with what was observed in bananas. This behavior suggests that there is a concentration of the water content in thiner samples due to natural causes, such as the internal structure. A sensorial analysis test revealed that panelists prefered the samples with lesser color change. As this conditions coincide with those in which the carotenoid content is less damaged $\mathrm{C}$. pubescens may be dried in slices at $60^{\circ} \mathrm{C}$ and $0.5 \mathrm{~cm}$ or $50^{\circ} \mathrm{C}$ and $1 \mathrm{~cm}$. 


\section{Acknowledgements}

Authors wish to thank Mr. William Bevalet for his editing help.

\section{References}

[1] McLeod, M.J.; Guttman, I.; Eshbaugh. H. Early evolution of chili peppers (Capsicum). Economic Botany 1982, 36(4), 361-368.

[2] Zewdie, Y.; Bosland, P. Combining ability and heterosis for capsaicinoids in Capsicum pubescens. HortScience 2001, 36(7), 1315-1317.

[3] Oboh, G.; Rocha, J. Distribution and antioxidant activity of polyphenols in ripe and unripe tree pepper (Capsicum pubescens). Journal of Food Biochemistry 2007, 31( 4), 456-473.

[4] Laborde, J.O.; Pozo C. Presente y Pasado del Chile en Mexico; INIA-SARH. Mexico, 1984

[5] Espinosa-Torres, L.E.; Ramírez-Abarca, O. Rentabilidad de chile manzano (Capsicum pubescens RYP) producido en invernadero en Texcoco, Estado de México. Revista Mexicana de Ciencias Agrícolas 2016, 7( 2), 325-335.

[6] Rodríguez-Burruezo, A.; Prohens, J.; Raigón, M.D.; Nuez, F. Variation for bioactive compounds in ají (Capsicum baccatum L.) and rocoto (C. pubescens R. \& P.) and implications for breeding. Euphytica 2009, 170(1-2), 169-181.

[7] Nguyen, M.; Price, W. Air-drying of banana: influence of experimental parameters, slab thickness, banana maturity and harvesting season. Journal of food engineering 2007, 79(1), 200-207.

[8] Hernández-Ortega, M., et al. Antioxidant, antinociceptive, and anti-inflammatory effects of carotenoids extracted from dried pepper (Capsicum annuum L.). BioMed Research International 2012, 2012, 1-10. 